\title{
Marine worm rewrites theory of brain evolution
}

Tools to build complex vertebrate brains assembled long before vertebrates had them.

\section{Amy Maxmen}

14 March 2012

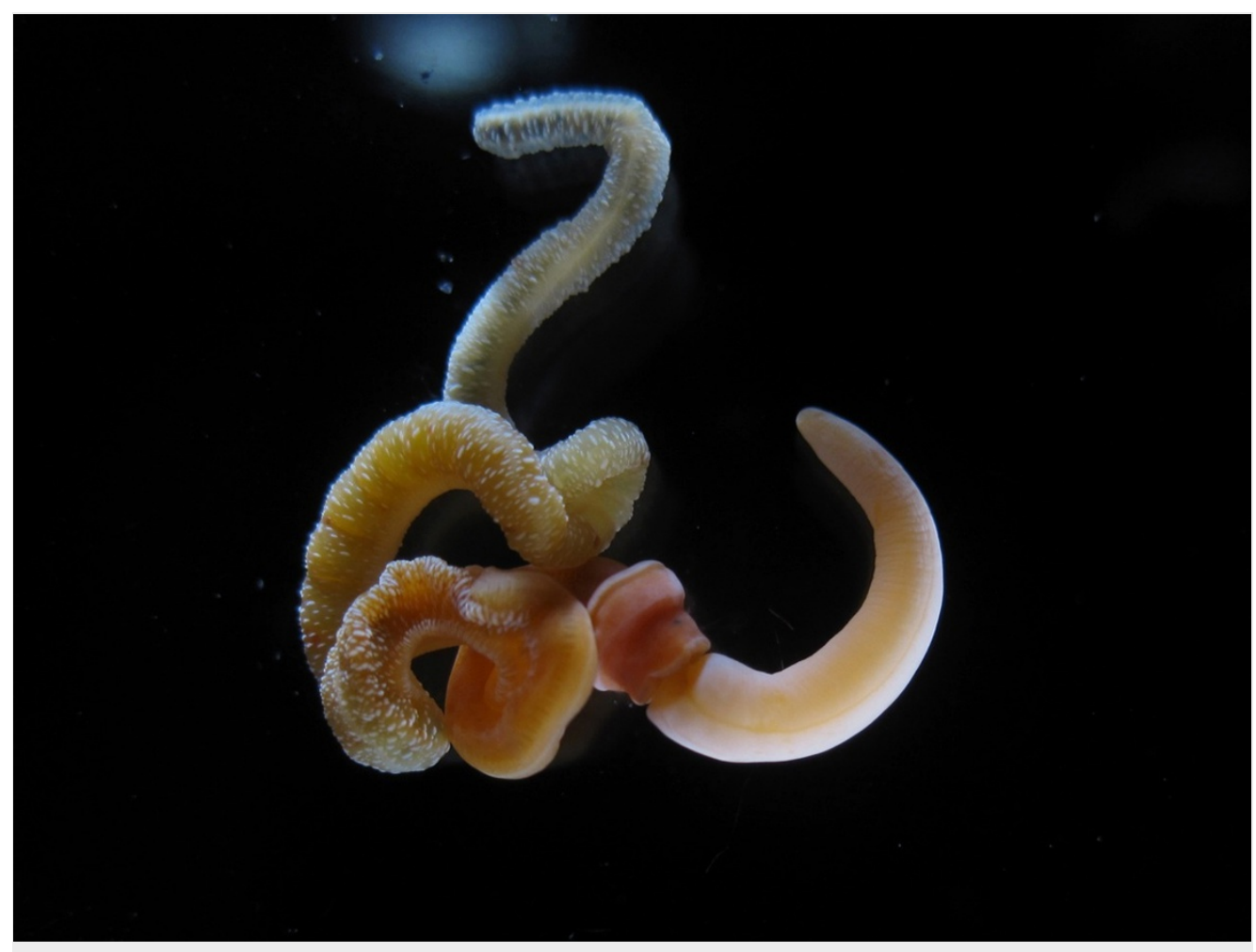

The adult acom worm is peppered with nerve cells, which have been dubbed a "skin brain".

A study on 'brainless' worms has shattered the theory that complex brains evolved entirely in vertebrates, long after they branched off from spineless species in the tree of life.

"This paper will change the way people think about brain evolution," says Chris Lowe, an evolutionary biologist at Stanford University's Hopkins Marine Station in Pacific Grove, California, and an author on the study, published today in Nature ${ }^{1}$.

To learn about the origin of the vertebrate brain, researchers tend to look to the group's relatives. Studies of vertebrates' closest living invertebrate kin have previously confirmed the uniqueness of the vertebrate brain. This complex three-part structure and the system of proteins that helps to guide its formation are missing or incomplete in two types of marine invertebrate - sea squirts and the fish-like lancelets - that bear a rod of tissue called a notochord along their backs, as vertebrates do, but not the spine to support it.

However, Lowe and his colleagues reopened the case to study the development of an invertebrate on the next branch of the evolutionary tree. These animals, acorn worms, burrow into sand on the sea floor, sense their surroundings using an acorn-shaped tip at the end of a stretchy proboscis, and bear 'gill slits' like sharks and lancelets - the key characteristic uniting them with both vertebrates and notochord-bearing invertebrates.

\section{Brain training}

By tagging proteins with markers, Lowe and his co-workers found that embryonic acorn worms they studied (Saccoglossus kowalevskii) express the three protein combinations in comparable regions of the embryo as vertebrates during the development of their three-part brains. In vertebrates, the three protein 'signalling centres' dictate where the forebrain, midbrain and hindbrain will form in later stages of development. In acorn worm embryos, a forebrain-like signalling centre switches on in the proboscis; a midbrain-like one is active in the collar of tissue just below the 
proboscis; and a hindbrain-like centre can be found where the collar meets the worm's trunk.

What's more, Lowe's team demonstrated that proteins in each signalling centre interact with one another in much same way that they do in vertebrates. The main difference is that the worm never forms a distinct brain. Instead, nerve cells speckle the proboscis and collar, forming what Lowe calls a "skin brain".

Biologists had assumed that the signalling centres had first come together in vertebrates because they were not observed in sea squirts or lancelets, says Cliff Tabin, a developmental and evolutionary biologist at Harvard Medical School in Boston. "I'd expect different animals to have similar genes, but it was a real surprise for me to see that these genes are expressed as proteins in the same signalling centres, and in the same location relative to one another."

Tabin says that the similarities cannot be a coincidence, and that the signalling centres must have evolved long ago in a common ancestor of acorn worms, vertebrates and the notochord-bearing invertebrates in between. The centres' nearly complete absence from sea squirts and lancelets suggests that, in these creatures, they were lost over evolutionary time.

\section{Tips of the tree}

The conclusion that lancelets had lost the signalling centres that had evolved in earlier species was "one of the biggest surprises to me", says Lowe. "Everyone looks at them as a living fossil — that's where this dogma on the evolution of the vertebrate brain came from."

Evolutionary biologist Billie Swalla at the University of Washington in Seattle says the research shows that biologists must look at many different animals when they try to decipher the origins of body parts that arose more than half a billion years ago. "We're looking at just the tips of the tree of life," she says.

The report leaves open the question of what brain signalling centres do in an essentially brainless worm. Lowe suggests that the centres help to design the network of nerves and the tissue that surrounds them. Meanwhile, Swalla speculates that they might underlie hidden sophistication. "I bet they do really complicated stuff that's not easy for us to see because it occurs in mud, under the water," she says. "l'd like to get a worm farm that resembles an ant farm so that I can film what they do when we're not looking."

Nature | doi:10.1038/nature.2012.10226

\section{References}

1. Pani, A. M. et al. Nature 483, 289-294 (2012). 